\title{
Topographical Development of the Supraoptic Nucleus of the Rat
}

\author{
M. A. Lazcano, M. L. Bentura and I. Carrato \\ Instituto Cajal, Consejo Superior de Investigaciones Cientificas, Madrid, Spain
}

Received August 17, 1987 ; Revised manuscript received February 15, 1988

\begin{abstract}
Summary. Topographical changes in the development of the principal part of the supraoptic nucleus (SON) of the rat were studied by analyzing its tridimensional images, from the intrauterine to the senescent stage. Evaluation of the growth rate of the SON was also made possible by this procedure. From the onset of the appearance of the SON, changes in its spatial orientation were marked by a progressive increase in the antero-posterior and medio-lateral dimensions. The ventro-dorsal one increased up to 6 months of age and then began to decrease progressively. These changes were accompanied by a ventral displacement that became indistinct at 6 months, whereas the lateral migration persisted. No rostro-caudal displacement was recognized. Possible reasons for these changes are briefly discussed.
\end{abstract}

The supraoptic nucleus (SON) lies in the ventrolateral zone of the anterior hypothalamus. Its most prominent part is not far away from the lateral end of the optic chiasm, and spreads laterally over the dorsal part of the optic tract. Posteriorly, it disappears at the level of the tuber cinereum.

RAMON y CAJAL (1911) was first to describe the SON as a neuronal group, calling it the "nucleus perichiasmaticus" and, also, the "tangentialis," although this latter name is prone to be mistaken with the nucleus tangentialis acousticus. It was LoO (1931) who finally used the present name of SON.

Like most of the hypothalamic nuclei, the SON lies in symmetrical pairs along both sides of the third ventricle. Each nucleus is, in turn, made up of another two parts: the principal one (BANDARANAYAKE, 1971; RHODES et al., 1981) consisting of more than $80 \%$ of the whole number of the neurons and corresponding to CAJAL's nucleus tangentialis (NAUTA and HAYMAKER,
1969); and the other part just under the principal one, being variously considered: by SZENTAGOTHAI et al. (1962) as the accessory nucleus, as the nucleus tuberalis by BODIAN and MAREN (1951), and as the diffuse supraoptic nucleus by NAUTA and HAYMAKER (1969). In the present paper, only the principal part of the SON will be considered.

Many authors have dealt with the nucleus from several approaches and in different species, enumerating its morphological peculiarities (CARRATO, 1952; SZENTAGOTHAI et al., 1962; LE FrANC, 1966; LUQUI and FoX, 1976; FELTEN and CASHNER, 1979; ARM Strong et al., 1982; BRUni and Perumal, 1984) and its functional importance (SCHARRER and SCHARRER, 1954 ; ZAMBRANO and DE ROBERTIS, 1966; VANDESAN. DE and DIERICKX, 1975, 1976; GoOSSENS et al., 1977; VANDESANDE and DIERICKX, 1979; SOFRONIEW et al., 1979; RHODES et al., 1981; KAWATA and SANO, 1982). Nevertheless, the architectonic characteristics of this neuronal group, as a whole, have been but scantily considered. RAMOS and collaborators (1982) did study some topographical traits of the SON through four stages of the life: three embryonic and one postnatal.

The present study evaluates the topographic changes of the SON that take place during a longer period of life, including the embryonic, juvenile, adult and senile stages. In this way, a more comprehensive overview of the age differences of the SON could be obtained. A system of morphometric data has been made available for us and this allowed a definition of the nucleus in terms of quantitative parameters, and also permitted the following of changes undergone during the embryonal, juvenile, adult and senescent periods. Semiautomatic methods in image analysis have been helpful in obtaining a tridimensional reconstruction of the SON at each period, and enabled us to store the data for any future comparative studies. 


\section{MATERIALS AND METHODS}

Twelve groups of five albino Wistar rats were employed. They were grouped according to the following ages: 18, 19, 20, 22 and 23 intrauterine days of life; 15 postnatal days of life; and 1, 3, 6, 12, 18 and 30 months of age. The embryos were always obtained from female rats of 3-6 months. The first day of pregnancy was determined by the appearance of spermatozoa in vaginal smears (COGGESHALL, 1964;
IfFT, 1972; MCALLISTER and DAS, 1977). Brains were fixed by a transcardial perfusion with Bouin solution in adult animals, and by directly immersing them in the same fixative for prenatal and new-born animals. Thereafter, brains were embedded in paraffin and cut in serial sections parallel to the frontal plane, and then stained with hematoxylin-eosin. Special care was taken to preserve the bilateral symmetry of all hypothalamic nuclei.

The outline of the SON at sequential histological sections was delineated $(100 \times)$ on each of the com-

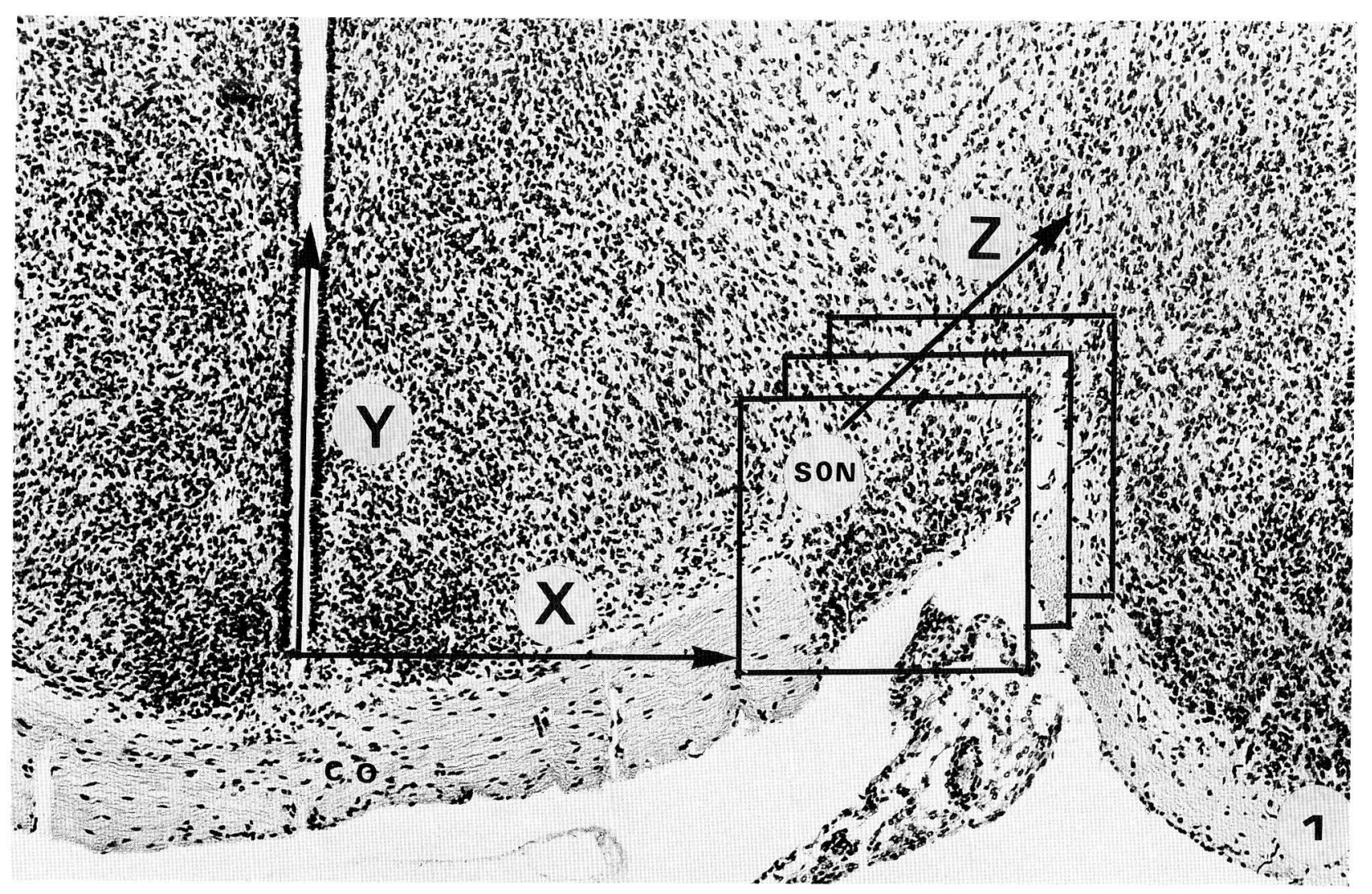

Fig. 1. Microphotography of a frontal section of the rat hypothalamus. The topographic axis and reference planes for the tridimensional reconstruction of the SON are represented. C.O optic chiasm, $X$ medio-lateral axis, $Y$ ventrodorsal axis, $Z$ antero-posterior axis.

Fig. 2. Coronal section of the anterior part of the $S O N$ of a 15-day-old rat. C.O optic chiasm.

Fig. 3. Coronal section of the medial part of the $S O N$ in a 15 day-old rat.

Fig. 4. Coronal section of the posterior part of the $S O N$ in a 15-day-old rat.

Fig. 5. Coronal section of the medial part of the SON of an 18 day embryo. The section of the $S O N$ is situated obliquely to the third ventricle.

Fig. 6. Coronal section of the medial part of the $S O N$ in a month-old rat. The section of the $S O N$ is situated in a position parallel to the third ventricle.

Fig. 7. Coronal section of the posterior part of the SON of embryos. The optic tract divides the posterior part of the $S O N$ into two asymetrical parts. 

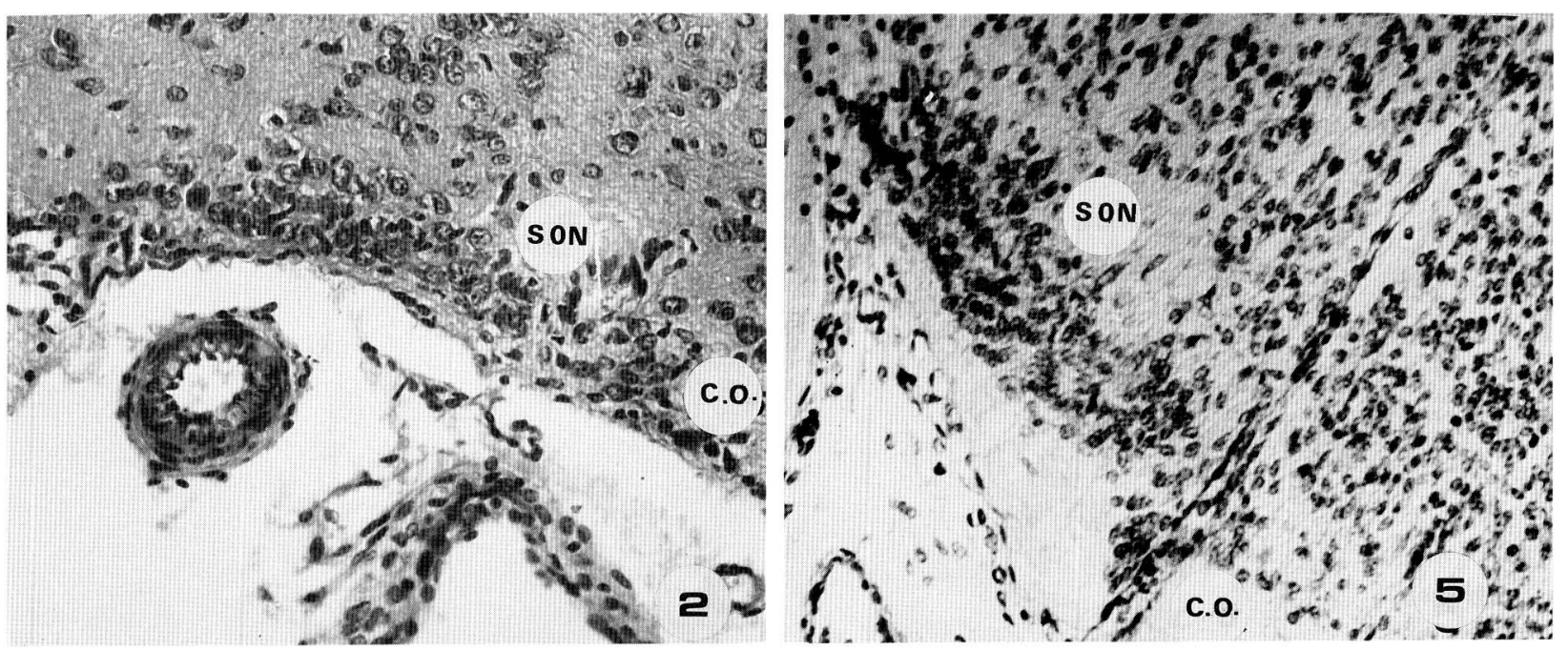

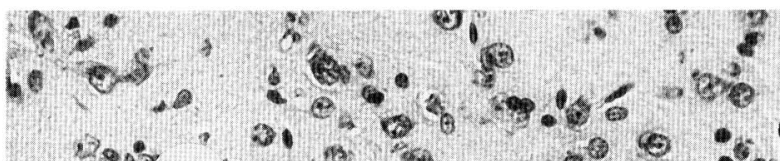

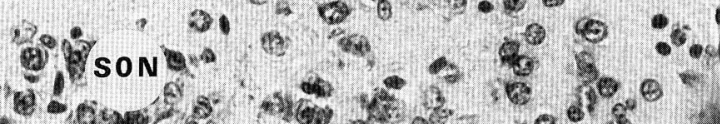
,

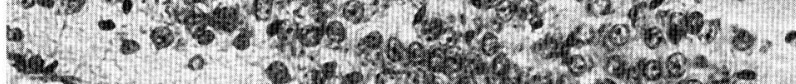

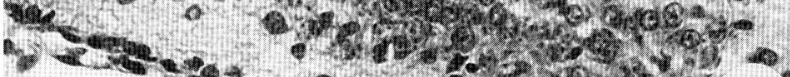

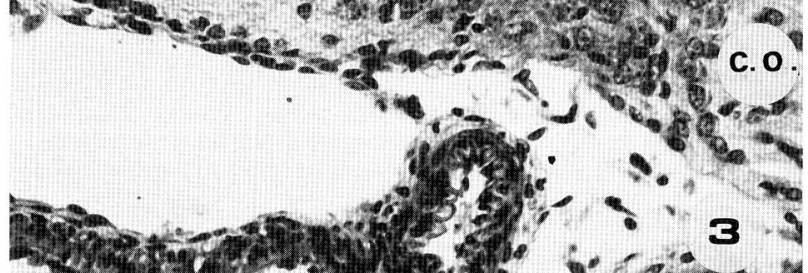

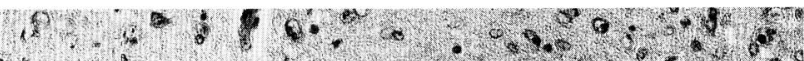

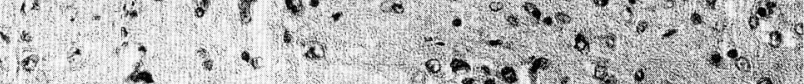

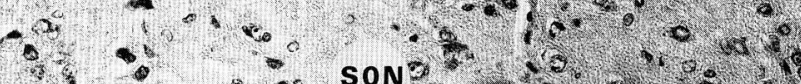

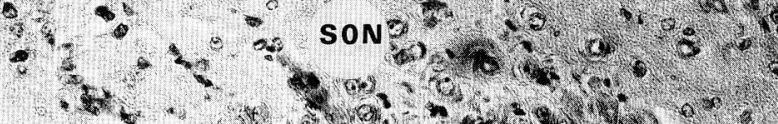

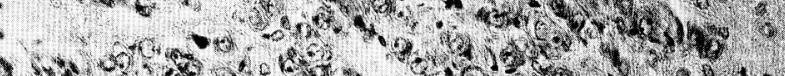

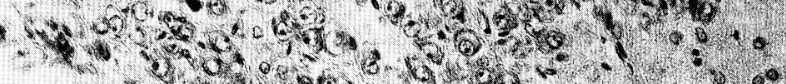

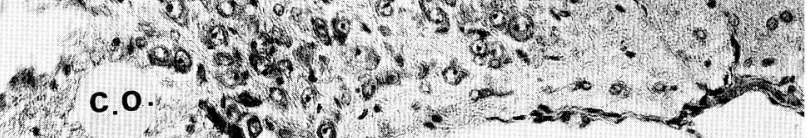

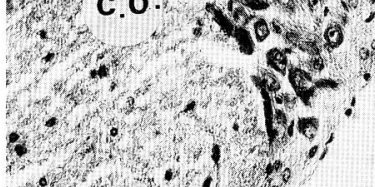
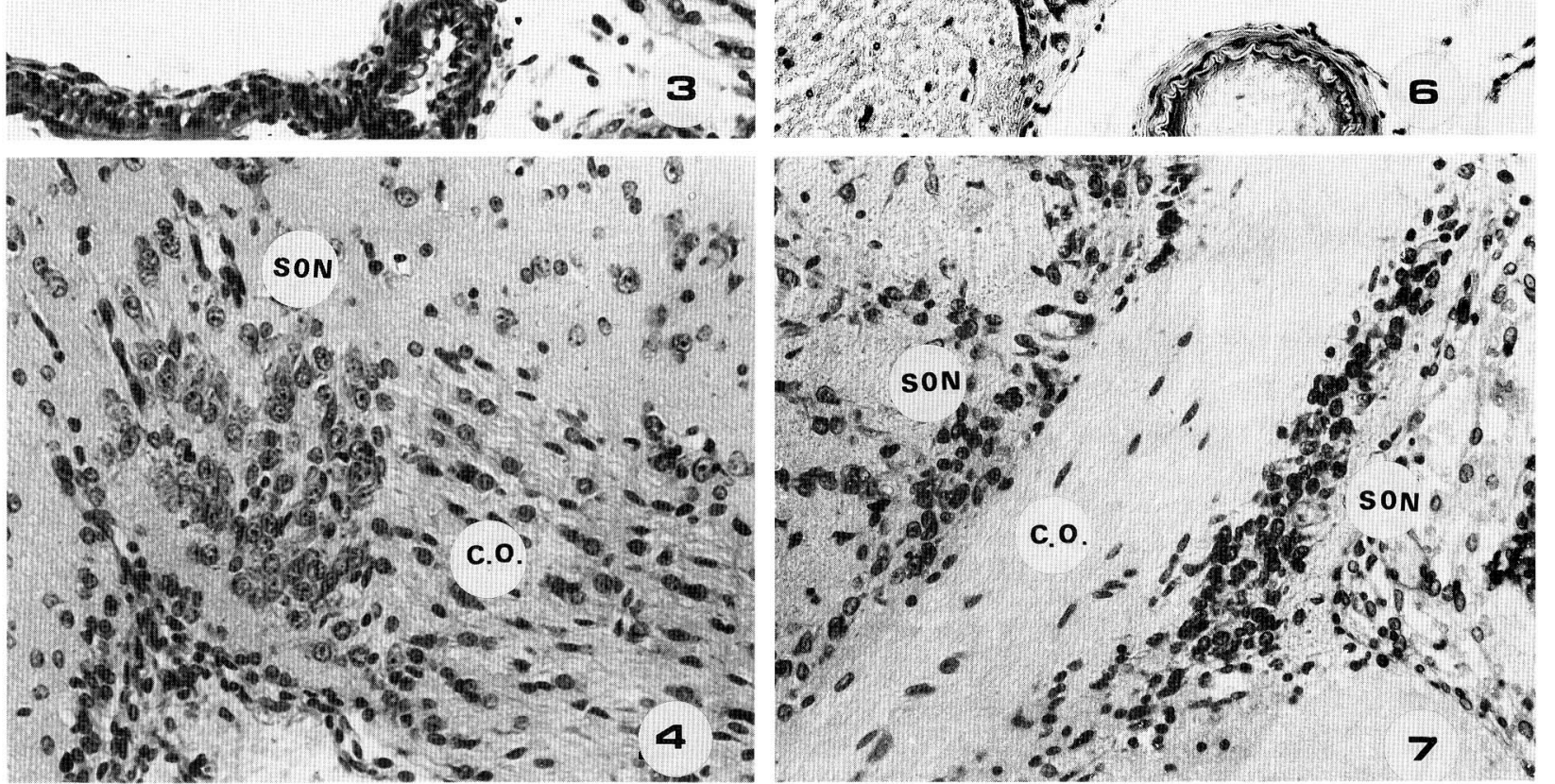

Fig. 2-7. Legends on the opposite page. 
plete series. With the help of a camera lucida, precise drawings were made with reference to two fixed coordinates: the horizontal line at the base of the third ventricle ( $\mathrm{X}$ axis), and the mid-line of the third ventricle ( $\mathrm{Y}$ axis). The $\mathrm{Z}$ axis is any one perpendicular to the plane formed by both $\mathrm{X}$ and $\mathrm{Y}$.

These series of outline drawings were processed for image analysis with semiautomatic equipment (IBAS I Kontron) using two programs: a "3D" program that converts any given bidimensional image into a tridimensional one from serial sections; and an "IBAS I" program that facilitates collection of parametrical data, such as the areal and growth rate values.

By superimposing the drawings of the outlines of the SON in a complete series of histological sections, the computer (" $3 \mathrm{D}$ " program) builds a tridimensional reconstruction of the SON and represents a graph of the figure from its front (frontal view). It thus becomes possible to visualize any projection view of the image: frontal, lateral or dorsal (Fig. 1). The morphological and topographical features of the SON were evaluated from these three computer perspectives.

\section{RESULTS}

In the first section of all the frontal series, the SON appeared as a band of disperse neurons (Fig. 2). The cellular density increased as one went backwards (Fig. 3), and the SON presented a more compact appearance. The caudal part of the nucleus becames less dense and lay over the dorsal part of the optic tract (Fig. 4). Moreover, at each growth stage there was some noteworthy specific trait. In embryos from 18 through 23 days, the positions of the SON are placed obliquely with regard to the plane of the third ventricle (Fig. 5). Through the lateral perspective, it could be deduced (Figs. 8b, 9b, 10b) that the angle between the ventricular midline axis and the centerline of the SON increases with the SON, approaching a horizontal position during its life. All these changes occur concurrently with the growth of the animal (Fig. 6).

During the embryonic and juvenile stages, fibers of the optic tract penetrate into the caudal part of the nucleus and divide it into two asymmetrical zones, ventral and dorsal (Fig. 7). This feature usually disappears at the age of one month, although it may appear again sporadically. The tridimensional perspective of the nucleus was carried out by a size analysis of the arrangement of the SON in the frontal sections, with reference to the three planes: the middle-lateral axis $(\mathrm{X})$, the ventro-dorsal axis $(\mathrm{Y})$, and the antero-posterior axis (Z) (Figs. 8a, 9a, 10a; 8b, $9 \mathrm{~b}, 10 \mathrm{~b} ; 8 \mathrm{c}, 9 \mathrm{c}, 10 \mathrm{c})$. Tables 1 and 2 summarize the data from which we established the exact position of the nucleus at each stage of its development.

\section{Fetal stage}

The SON grows in all three dimensions with increased rates along the $\mathrm{X}(103 \%)$ and $Z$ (96\%) axes. The growth rate is constant along the $\mathrm{Y}$ axis; discontinuous, with important variations in some stages along the $\mathrm{X}$ and $Z$ axes (Table 1; Figs. 8a: 18d, 19d, 20d, 22d; 9a: 23d).

Morphologically, the SON shows an irregular shape, the anterior and posterior parts being smaller than the intermediate one (Fig. 8a). The ventral part is more medial than the dorsal one, whereas the caudal part is more dorsal and lateral than the anterior one. All these data have been verified from the lateral and dorsal views (Figs. 8b, c).

Optic tract fibers cross the nucleus during this stage and divide the caudal area into two sections (Figs. 7; 8a: 19d).

This study was begun on the 18th day of gestation; on this day, as well as the 19th, the SON is located above the base of ventricle III. From the 20th day until the rat is 30 months old, the dorsal zone is positioned above the reference axis (Figs. 8, 9, 10a, b).

Until the 20th fetal day, the most medial part corresponds to the intermediate territory (Figs. 8c: $18 \mathrm{~d}, 19 \mathrm{~d}, 20 \mathrm{~d}$ ). After this day, the anterior part occupies the most medial position, whereas the caudal part always represents the most lateral position.

Briefly, the lateral movement that takes place during the fetal stage is less than that of the ventral movement (Table 2).

\section{Juvenile stage}

Growth of the SON after birth is constant along the three dimensions. As in the fetal stage, and during the interval from birth to one month of age, the most important expansion takes place in an anteroposterior direction (58\%), corresponding to an important increase in the medio-lateral direction (38\%). Growth is far slower along the ventro-dorsal axis (4.8\%) than the previous two directions (Table 1).

The position of the SON during this stage is similar to that during the fetal stage. The caudal part is more dorsal (Figs. 9b: 15d, 1m) and more lateral (Figs. 9c: 15d, 1m) than the anterior one. This last characteristic is constant during the entire life span 


\section{RAT SUPRAOPTIC NUCLEUS}
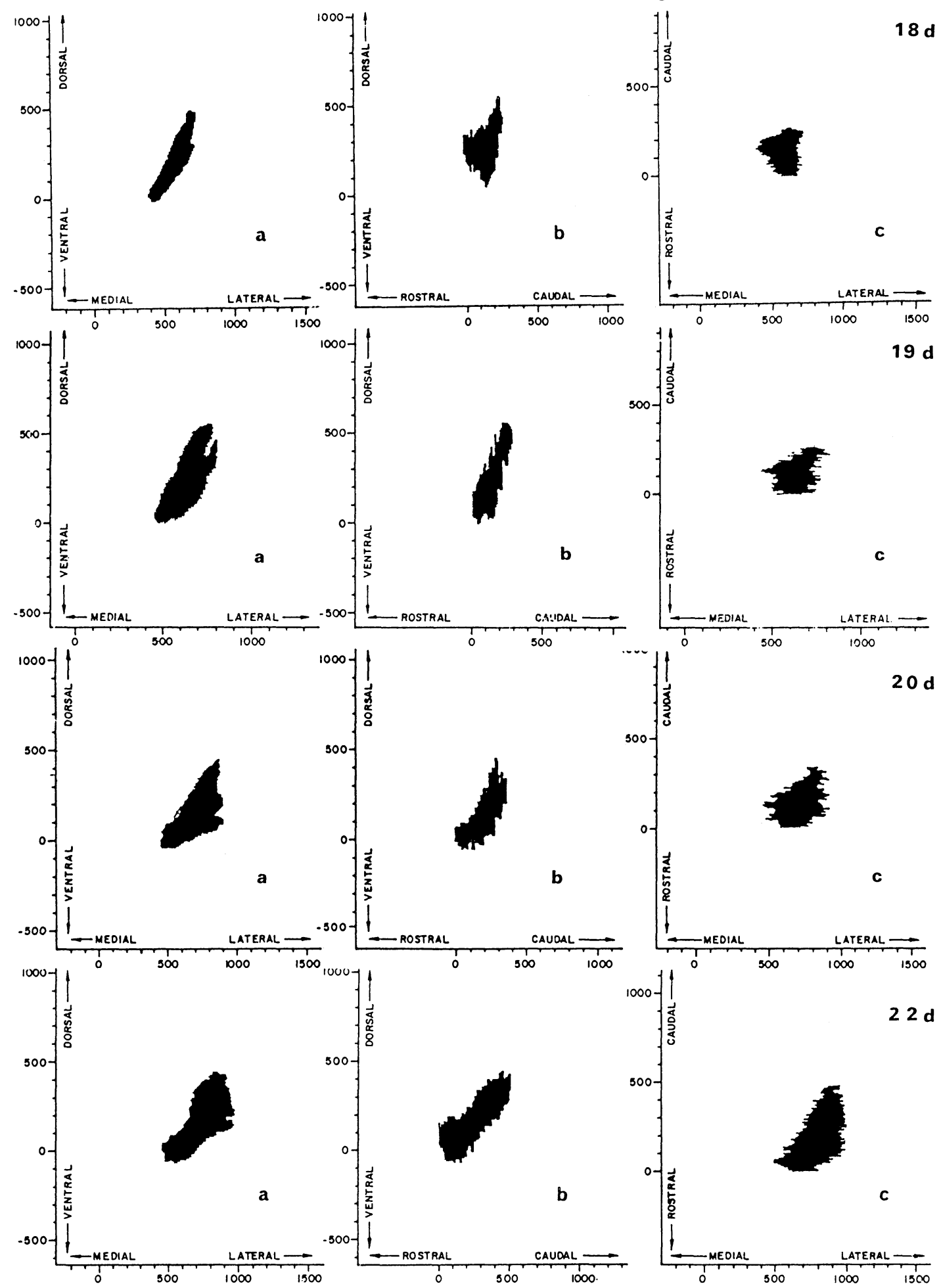

Fig. 8, 18d-22d. Tridimensional reconstruction of the SON in rat embryos 18, 19, 20 and 22 days old. a: Frontal view, $\mathbf{b}$ : lateral view, $\mathbf{c}$ : dorsal view. 

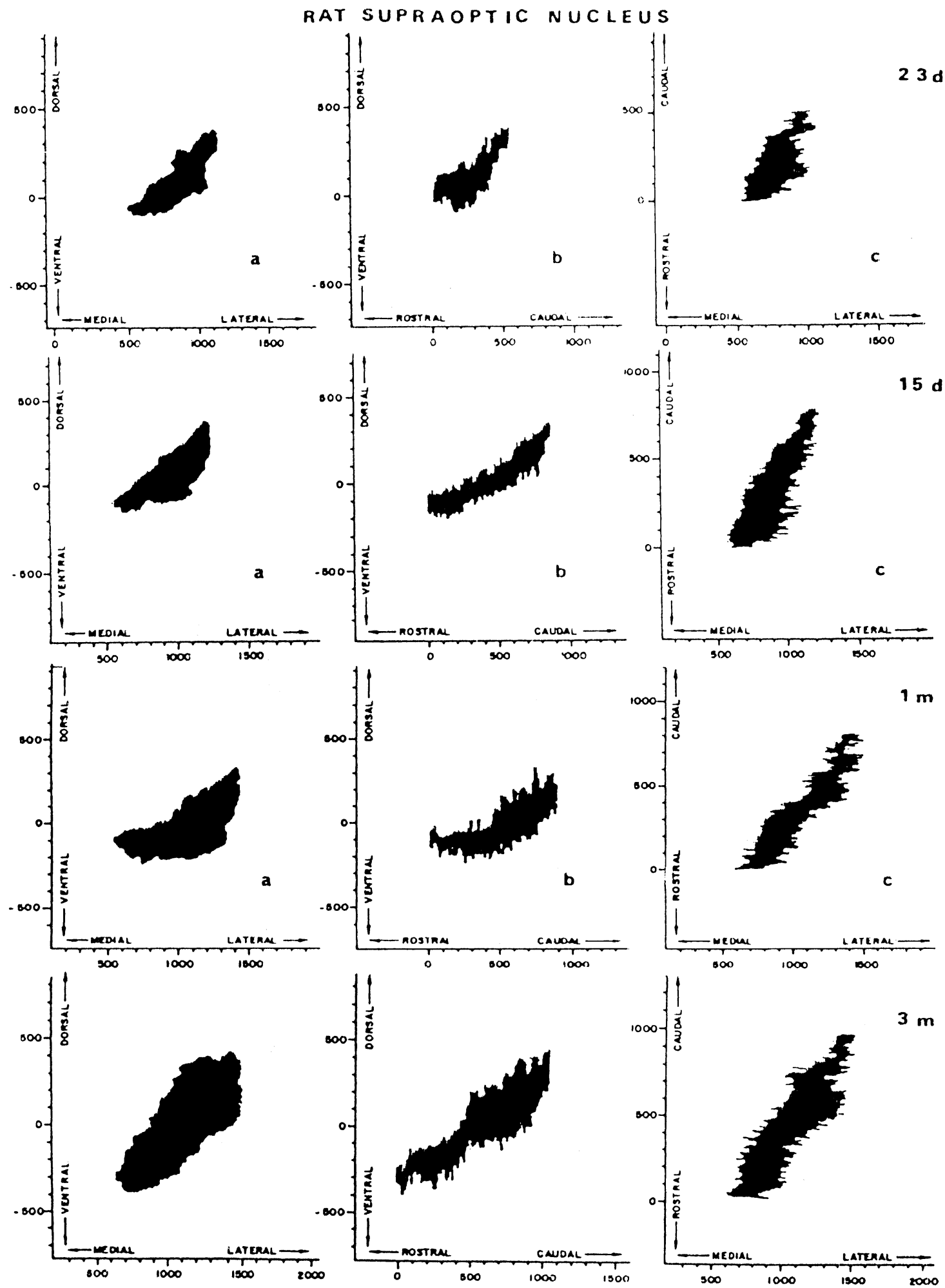

Fig. 9. Tridimensional reconstruction of the SON of 23 day embryos (23d), 15-days-old (15d), 1-month(1m) and 3-month-old (3m) animals. a: Frontal view, b: lateral view, c: dorsal view. 

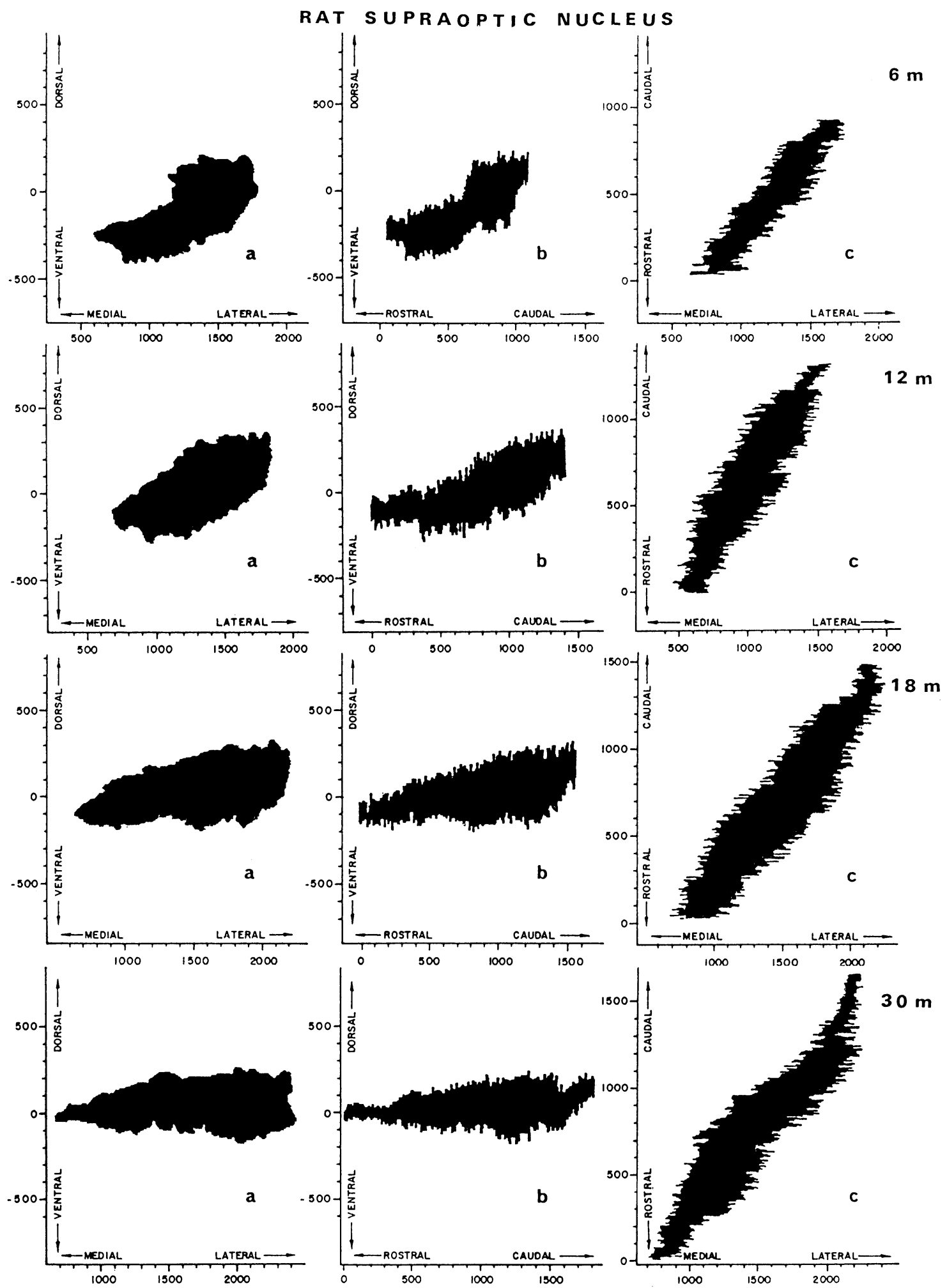

Fig. 10, 6m-30m. Tridimensional reconstruction of the SON in 6,12, 18 and 30-month-old rats. a: Frontal view, b: lateral view, $\mathbf{c}$ : dorsal view. 
Table 1. The dimensions of the three axes of the SON at different ages. Means and standard deviations of the sizes $(\mu \mathrm{m})$ of the $X, Y$ and $Z$ axes are shown. These values were obtained from tridimensional reconstruction

\begin{tabular}{cccr}
\hline & \multicolumn{3}{c}{ Axes size } \\
\cline { 2 - 4 } Ages & $\mathrm{X}$ & $\mathrm{Y}$ & $\mathrm{Z}$ \\
\hline E18d & $310 \pm 15$ & $490 \pm 13$ & $260 \pm 30$ \\
E19d & $320 \pm 17$ & $517 \pm 10$ & $280 \pm 20$ \\
E20d & $428 \pm 17$ & $535 \pm 25$ & $350 \pm 30$ \\
E22d & $450 \pm 20$ & $548 \pm 35$ & $490 \pm 30$ \\
E23d & $608 \pm 30$ & $556 \pm 30$ & $530 \pm 50$ \\
$15 \mathrm{~d}$ & $650 \pm 25$ & $562 \pm 21$ & $780 \pm 40$ \\
$1 \mathrm{~m}$ & $840 \pm 30$ & $583 \pm 19$ & $840 \pm 60$ \\
3m & $1,016 \pm 54$ & $854 \pm 25$ & $1,000 \pm 90$ \\
$6 \mathrm{~m}$ & $1,233 \pm 28$ & $901 \pm 30$ & $1,280 \pm 80$ \\
$12 \mathrm{~m}$ & $1,297 \pm 100$ & $649 \pm 20$ & $1,340 \pm 70$ \\
$18 \mathrm{~m}$ & $1,484 \pm 80$ & $536 \pm 12$ & $1,510 \pm 90$ \\
$30 \mathrm{~m}$ & $1,644 \pm 43$ & $448 \pm 14$ & $1,770 \pm 80$ \\
\hline
\end{tabular}

Table 2. Distance of the SON from the reference planes. Distal and proximal separation $(\mu \mathrm{m})$ of the SON from the reference planes at each of the selected ages. These values are referred to in the tridimensional reconstruction shown in Figures 1, 2 and 3. The area proximal to the frontal plane is not mentioned since it does not vary during the rat's life

\begin{tabular}{|c|c|c|c|c|c|}
\hline \multirow{2}{*}{ Ages } & \multicolumn{2}{|c|}{$\begin{array}{l}\text { Distance to the } \\
\text { sagital plane } \\
x\end{array}$} & \multicolumn{2}{|c|}{$\begin{array}{c}\text { Distance to the } \\
\text { horizontal plane } \\
\mathrm{Y}\end{array}$} & \multirow{2}{*}{$\begin{array}{c}\text { Distance to the } \\
\text { frontal plane } \\
Z \\
\text { Dis. }\end{array}$} \\
\hline & Prox. & Dis. & Prox. & Dis. & \\
\hline E18d & 402 & 712 & 58 & 548 & 260 \\
\hline E19d & 450 & 770 & -14 & 503 & 280 \\
\hline E20d & 451 & 879 & -48 & 486 & 350 \\
\hline E22d & 475 & 925 & -77 & 471 & 490 \\
\hline E23d & 491 & 1,099 & -116 & 440 & 530 \\
\hline $15 \mathrm{~d}$ & 560 & 1,210 & -168 & 394 & 780 \\
\hline $1 \mathrm{~m}$ & 572 & 1,412 & -250 & 333 & 840 \\
\hline $3 \mathrm{~m}$ & 595 & 1,611 & -393 & 461 & 1,000 \\
\hline $6 \mathrm{~m}$ & 615 & 1,848 & -443 & 457 & 1,280 \\
\hline $12 \mathrm{~m}$ & 649 & 1,946 & -298 & 350 & 1,340 \\
\hline $18 \mathrm{~m}$ & 680 & 2,164 & -200 & 336 & 1,510 \\
\hline $30 \mathrm{~m}$ & 702 & 2,346 & -183 & 265 & 1,770 \\
\hline
\end{tabular}

Table 3. Differences in the growth rates of the SON. Results of the growth in each axis for one day

\begin{tabular}{lcccr}
\hline & Embryonic & Neonatal & Adult & \multicolumn{1}{c}{ Senile } \\
\hline $\mathrm{X}$ axis & $59.6 \mu \mathrm{m}$ & $4.5 \mu \mathrm{m}$ & $1.0 \mu \mathrm{m}$ & $0.64 \mu \mathrm{m}$ \\
$\mathrm{Y}$ axis & $13.2 \mu \mathrm{m}$ & $3.3 \mu \mathrm{m}$ & $0.7 \mu \mathrm{m}$ & $-0.37 \mu \mathrm{m}$ \\
$Z$ axis & $54.0 \mu \mathrm{m}$ & $5.2 \mu \mathrm{m}$ & $1.2 \mu \mathrm{m}$ & $0.80 \mu \mathrm{m}$ \\
\hline
\end{tabular}




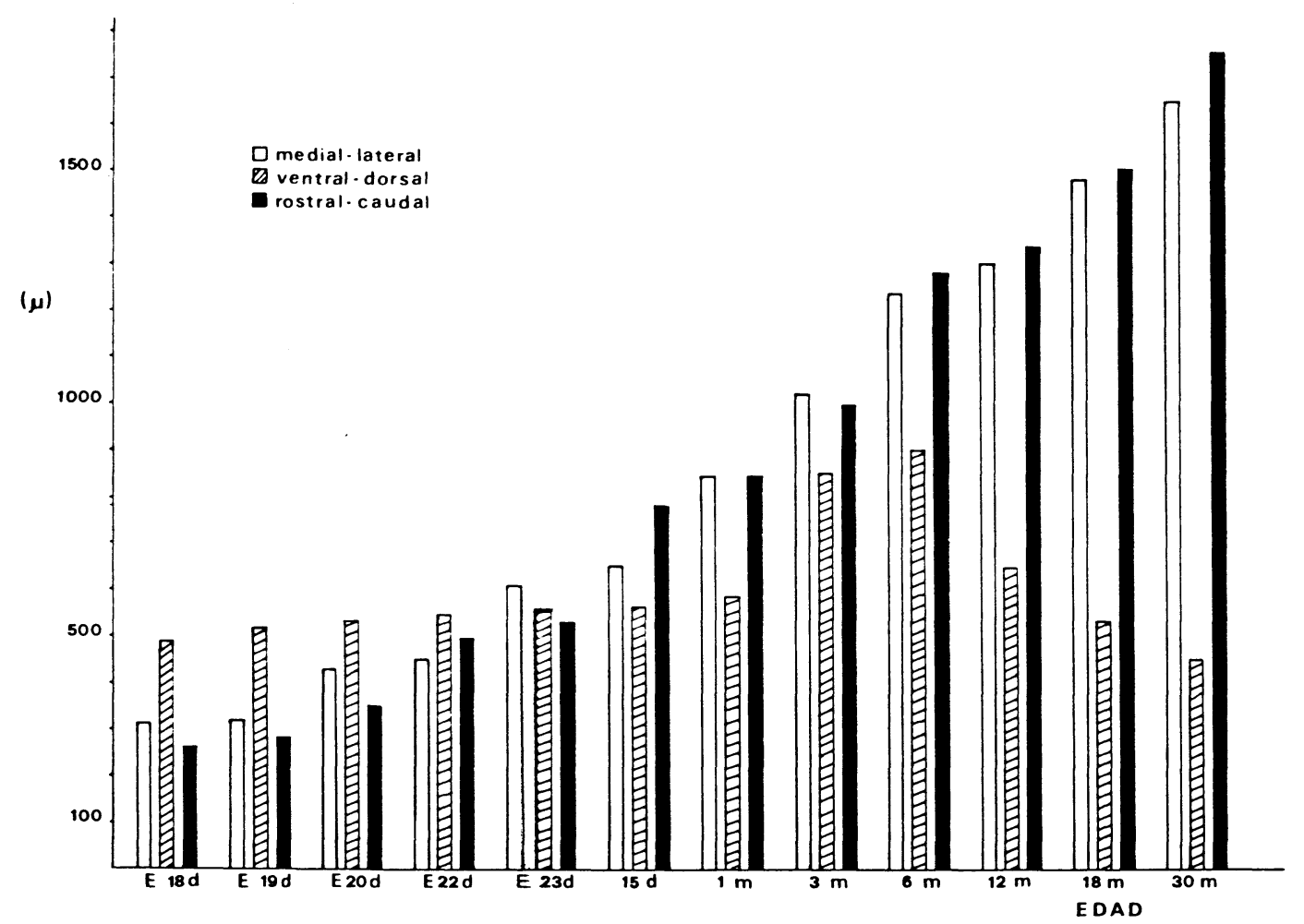

Fig. 11. The dimensions in $\mathrm{X}, \mathrm{Y}$ and $\mathrm{Z}$ axes of the SON in different ages of rat. Relation among the three dimensions of the SON at each age; corresponding growth rates are demonstrated. The $\mathrm{Y}$ axis defines the involution of the nucleus.

of the rat (Figs. 9b, c, 10b, c). There is also an important ventral descent and a lateral displacement. The latter is minimal at the medial border but very noticeable in the lateral view of the SON (Table 2).

\section{Adult stage}

During the adult stage the SON reveals important morphological changes. From 3 to 6 months of age the nucleus grows in a similar manner in all three directions: $46 \%$ at the $\mathrm{X}$ axis; $54 \%$ at the $\mathrm{Y}$ axis; and $52 \%$ at the $Z$ axis. The change along the $\mathrm{Y}$ axis characterizes the adult stage, reaching maximal length in the ventro-dorsal direction at 6 months of age (Table 1). From the 6th month the growth in this direction decreases. At 12 months there is an important reduction (28\%) in the ventro-dorsal size, establishing a similar trend for this in all the senile stages (Table 1) (Fig. 11).

The lateral movement is still greater in the caudal part than in the anterior one of the SON. Nevertheless, ventral displacement ceases in the 6-month-old animal in the anterior part of the nucleus, but persists in the caudal zone (Table 2) (Figs. 10b: 6m, 12m).

\section{Senile stage}

At the beginning of involution, the morphological traits of the SON undergo many changes, the most outstanding being a progressive decrease in diameter along the ventro-dorsal axis, in parallel with a continuous descent of the caudal part of the nucleus (Figs. 10b: 18m, 30m), (Tables 1, 2). The anterior and the posterior parts reach a similar ventro-dorsal position. The growth rates in the $\mathrm{X}$ axis and the $Z$ axis are $31 \%$ and $32 \%$, respectively. Ventral displacement occurs only in the caudal zone, which still presents a lateral displacement that has been constant during growth. In the last stage of the rat's life, the SON adopts a position almost perpendicular to the plane of the third ventricle.

In order to study the spatial growth rate of the nucleus, we used the value of one-day growth for each axis; thereby, the differences between rates became more evident. The SON grows, of course, in all directions during life, but the growth rate slows with age (Table 3).

The growth rate of the $\mathrm{X}$ axis goes from $59.6 \mu \mathrm{m}$ 
per day in the embryonic stage to $0.64 \mu \mathrm{m}$ in the senile one, emphasizing an important reduction in the growth rate according to the age of the rats.

The same occurs with the $Z$ axis, showing values that go from $54.0 \mu \mathrm{m}$ in the embryonic stages to 0.8 $\mu \mathrm{m}$ in the senile ones (Table 3 ).

The $\mathrm{Y}$ axis grows at smaller rates $(13.2 \mu \mathrm{m} /$ day in the embryonic phase, $3.3 \mu \mathrm{m} /$ day in the juvenile phase, and $0.7 \mu \mathrm{m}$ in the adult phase), but increases slightly until the end of the adult phase. In the senile stage, there occurs a small reduction of $0.37 \mu \mathrm{m} /$ day in this axis due to ventral displacement of the posterior part of the nucleus.

\section{DISCUSSION}

Previous papers (GURDJIAN, 1927; GILBERT, 1935; CogGeshall, 1964; Altman and BAYer, 1978) have considered the SON, as a whole, to be either isolated or related with other hyphothalamic nuclei, from several points of view. Nevertheless, little is known about its ontogenic development (COGGESHALL, 1964; HYYPPÄ, 1969; IFFT, 1972; RAMOS et al., 1982) as an isolated nucleus from the time of its appearance through its growing condition to the senescent period. In order to carry out this type of study, we have chosen the SON as the most outstanding feature among its surroundings, and therefore can determine the outline of the nucleus as well as refer to the obtained data for establishing topographic guidelines. The SON fulfills all of these requirements. In addition, due to its special location in the brain, studies can pursue its ontogenic development. Moreover, this study may also serve as an indicator of diencephalic growth.

The structure of the SON undergoes progressive changes from the embryonic to the senile stages. These changes coincide with four phases of life: embryonic, juvenile, adult and senile. The only invariable trait is that the nucleus always appears wider in its intermediate portion than in either its proximal or distal ones (Figs. 8b, c, 9b, 10b, c).

With respect to the topography, during the initial embryonic stage, 18 intrauterine days, the intermediate zone occupies a more ventral position (Fig. 8b: 18d). Only a few hours before birth, the anterior zone has the most medial and ventral localization (Figs. $9 \mathrm{~b}, \mathrm{c}: 23 \mathrm{~d}$ ). This characteristic remains during the rest of life (Figs. 9, 10b, c). The optic tract fibers cross the nucleus, dividing its caudal position into two asymetrical parts. This condition persists until the neonatal stage (Fig. 7). In juvenile rats, the two parts fuse again and do not divide any further. In juvenile and adult rats, the topography of the SON is similar, showing progressive growth with time. At 18 months of age, the three nuclear zones occupy a similar ventro-dorsal position (Fig. 10b: 18m). The senile stage is characterized by the descent of the caudal zone to a more ventral level.

A sequential follow-up on the evolution of the tridimensional aspect of the SON suggests the following: 1) The SON presents continuous growth along the $\mathrm{X}$ and $\mathrm{Y}$ axes, and this growth is inversely proportional to the age. With regard to the $\mathrm{Y}$ axis, the growth is continuous until a certain period (6 months) of the adult phase. Then the $\mathrm{Y}$ axis reaches its greatest extension $(910 \mu \mathrm{m})$ in the ventro-dorsal direction. From this age there occurs an important reduction in this axis; this reflects the individuals' senility. It is believed that this decrease is produced as a consequence of the lowering of the caudal part of the SON toward more a ventral level, while the rostral part remains invariable in the ventro-dorsal position. 2) There is a change in the spatial position of the whole neuronal group. The nucleus reveals a turning movement of about 45 degrees in a latero basal direction, due to the development of the remaining diencephalic structures. 3) The maximal length of the most distal parts from the reference axes are the following ones: $1,634 \mu \mathrm{m}$ in the mid-lateral direction (X), $283 \mu \mathrm{m}$ in the ventro-dorsal (Y), and $1,510 \mu \mathrm{m}$ in the anteroposterior ( $Z$ ). From the beginning of the appearance of the SON, the proximal part does not vary along the anteroposterior direction. Its first frontal sections always coincide with the same territory of the optic chiasm.

All these changes might be determined by a differential growth tension that develops a dynamic adjustment to each component of the structure. Also to be considered are the local migrations undergone by some groups of neurons, in order to reach their difinite positions at different times. Only an exhaustive study of accurate morphometric data, in terms of necessary parameters along the life span of the animal, will be able to establish a satisfactory mathematical pattern of the development of the SON.

Acknowledgements. We would like to express our gratitude to Mrs. Blanca SANCHEZ for her technical assistance and to Dr Ljuba FRANIC for revising the manuscript. 


\section{REFERENCES}

Altman, J. and S. A. Bayer: Development of the diencephalon in the rat. II. Correlation of the embryonic development of the hypothalamus with the time of origin of its neurons. J. Comp. Neurol. 182: 973-993 (1978).

Armstrong, W. E., J. Schöler and T. H. Mc Neil: Immunocytochemical, Golgi and electron microscopic characterization of putative dendrites in the ventralglial lamina of the rat supraoptic nucleus. Neuroscience 7: 679-694 (1982).

Bandaranayake, R. C.: Morphology of the accessory neurosecretory nuclei and of the retrochiasmatic part of the supraoptic nucleus of the rat. Acta Anat. 80: 1422 (1971).

Bodian, D. and T. H. Maren: The effect of neuro- and adenohypophysectomy on retrograde degeneration in hypothalamic nuclei of the rat. J. Comp. Neurol. 94: 485-504 (1951).

Bruni, J. E. and P. M. Perumal: Cytoarchitecture of the rat's supraoptic nucleus. Anat. Embryol. 170: 129-138 (1984).

Carrato, A.: Aportaciones a la citologia del sistema hipotálamo hipofisiario. Trab. Inst. Cajal. Invest. Biol. XLIV : 159-209 (1952).

Coggeshall, R. E.: A study of diencephalic development in albino rat. J. Comp. Neurol. 122: 241-269 (1964).

Felten, D. L. and K. A. Cashner: Cytoarchitecture of the supraoptic nucleus: A Golgi analysis. Neuroendocrinology 29: 221-230 (1979).

GILbERT, M. S.: The early development of the human diencephalon. J. Comp. Neurol. 62: 81-115 (1935).

Goossens, N., K. DierickX and F. VANDESANDE: Immunocytochemical demonstration of the hypothalamo hypophysial vastocinergic system of Lampetra fuviatilis. Cell Tiss. Res. 177: 317-323 (1977).

GuRdjian, E. S.: The diencephalon of the albino rat. J. Comp. Neurol. 43: 1-114 (1927).

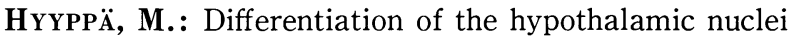
during ontogenetic development in the rat. Z. Anat. Entw.-Gesch. 129: 41-52 (1969).

IFFT, J. D.: An autoradiographic study of the time of final division of neurons in the rat hypothalamic nuclei. J. Comp. Neurol. 144: 193-204 (1972).

KAWATA, M. and Y. SANo: Immunohistochemical identification of the oxytocin and vasopressin neurons in the hypothalamus of the monkey (Macaca fuscata). Anat. Embryol. 165: 151-167 (1982).

LE Franc, G.: Estude neurohistologique des noyaux supraoptique et paraventriculaire chez le cobaye et le chat par la technique de triple impregnation de Golgi. C. R. Hebd. Seanc. Acad. Sci. Paris, D263: 976-979 (1966).

Loo, Y. T.: The forebrain of the opossum Didelphis virginiana. II. Histology. J. Comp. Neurol. 52: 1-148 (1931).

LuQUi, I. J. and C. A. Fox: The supraoptic nucleus and the supraopticohypophyseal tract in the monkey (Macaca mulatta). J. Comp. Neurol. 168: 7-40 (1976).

MCAllister, J. P. and G. D. DAs: Neurogenesis in the epithalamus, dorsal thalamus and ventral thalamus of the rat: An autoradiographic and cytological study. J. Comp. Neurol. 172: 647-206 (1977).

Nauta, W. J. H. and W. HAYMaker: Hypothalamic nuclei and fiber connections. In: (ed. by) W. HAYMAKER, E. Anderson and W. J. H. NAUTA: The hypothalamus. Thomas, Springfield, 1969 (p. 136-209).

RAMon Y CAJAL, S.: Histologie du système nerveux. Vol. 2. (Translated by Dr. Azoulay). C. S. I. C. Instituto Cajal, Madrid, 1955 (1911).

Ramos, M. V., M. L. Bentura and A. Toledano: Parametros citofotometricos en la caracterizacion de las celulas. Aplicacion al estudio del desarrollo embrionario y postnatal del nucleo supraoptico de la rata. Citologia $\mathrm{n}^{\circ}$ 1: 119-134 (1982).

Rhodes, C. H., J. I. Morrell and D. W. Pfaff: Immunohistochemical analysis of magnocellular elements in rat hypothalamus: distribution and numbers of cells containing neurophysin, oxytocin, and vasopressin. J. Comp. Neurol. 198: 45-64 (1981).

Scharrer, E. and B. ScharRer: "Hormones" produced by neurosecretory cells. Rec. Progr. Hormone Res. 10: 183-240 (1954).

Sofroniew, M. V., A. Weinde, I. Schinko and R. WETzSTEIN: The distribution of vasopressin-, oxytocin-, and neurophysin-producing neurons in the guinea pig brain. Cell Tiss. Res. 196: 367-384 (1979).

Szentagothai, J., B. Flerko, B. Mess and B. Halasz: Hypothalamic control of the anterior pituitary. Akadémia Kiado Budapest, 1962.

VANDESANDE, F. and K. Dierickx: Identification of the vasopressin producing and of the oxytocin producing neurons in the hypothalamic magnocellular neurosecretory system of the rat. Cell. Tiss. Res. 164: 153-162 (1975).

- Immunocytochemical demonstration of separate vasotocinergic and mesotocinergic neurons in the amphibian hypothalamic magnocellular neurosecretory system. Cell. Tiss. Res. 175: 289-296 (1976).

VAndesande, F. and K. Dierickx: The activated hypothalamic magnocellular neurosecretory system and the one neuron-one neurohypophysial hormone concept. Cell Tiss. Res. 200: 29-33 (1979).

Zambrano, D. and E. DE Robertis: The secretory cycle of supraoptic neurons in the rat. A structural-functional correlation. Z. Zellforsch. 73: 414-431 (1966).

Dr. M. Angeles Lazcano Instituto Cajal (C.S.I.C.)

C/Velazquez, 144 28006 Madrid Spain 